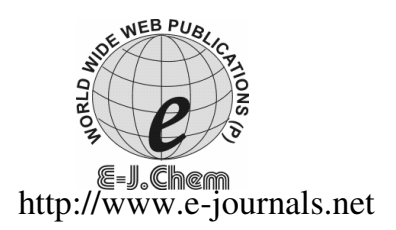

ISSN: 0973-4945; CODEN ECJHAO

E-Journal of Chemistry

2011, 8(4), 1490-1497

\title{
Palladium Nanoparticles Immobilized on Poly(vinyl chloride)-Supported Pyridinium as an Efficient and Recyclable Catalyst for Suzuki-Miyaura Cross-Coupling Reaction
}

\author{
BO ZHOU and YI-QUN LI* \\ Department of Chemistry, Jinan University \\ Guangzhou 510632, PR China \\ tlyq@jnu.edu.cn
}

Received 8 August 2010; Revised 19 November 2010; Accepted 15 December 2010

\begin{abstract}
The palladium nanoparticles immobilized on the polymeric surface of poly(vinyl chloride)-supported pyridinium $\left(\mathrm{PVC}-\mathrm{Py}_{-} \mathrm{Pd}^{0}\right)$ were achieved by a simple procedure by applying the corresponding functionalized polymer and palladium chloride in ethanol solution. The as-prepared catalyst (PVC-Py-Pd ${ }^{0}$ ) was found to be air and moisture stable and exhibits significant catalytic activity for Suzuki-Miyaura cross-coupling reaction of various aryl halides and phenylboronic acid under milder operating conditions. The procedure presented here showed several merits such as short reaction time, simple experimental and isolated procedure and excellent yields of products. Furthermore, the catalyst can be easily recovered and reused for at least six times with consistent activities.
\end{abstract}

Keywords: Nanopalladium, Poly(vinyl chloride), Pyridinium, Heterogeneous catalyst, SuzukiMiyaura reaction

\section{Introduction}

The palladium-catalyzed Suzuki-Miyaura cross-coupling reaction of aryl halides with arylboronic acids, is one of the most powerful tool for the preparation of unsymmetrical biaryl compounds ${ }^{1-5}$, which has been applied to many areas, including herbicides ${ }^{6}$ and natural product syntheses ${ }^{7-9}$. In the past decades, numerous efforts have been made to develop efficient catalyst systems for Suzuki-Miyaura cross-coupling reaction ${ }^{10-11}$. The traditional protocols for the Suzuki-Miyaura cross-coupling reaction prescribe a palladium species with phosphine ligands as the catalyst. However, phosphine ligands are expensive, poisonous, difficultly to recover, air sensitive and subject to $\mathrm{P}-\mathrm{C}$ bond degradation at elevated 
temperatures ${ }^{12}$. Therefore, the development of phosphine-free catalytic systems to overcome these drawbacks is considered to be one of the most challenging fields in organic chemistry. From the standpoint of environmentally benign organic synthesis, development of immobilized palladium catalysts is challenging and important ${ }^{13-15}$. In an ideal system, they can be recovered from the reaction mixture by simple filtration and re-used infinitely and contamination of products by palladium is prevented. Recently, the preparation and application of polymer-supported catalysts has drawn dramatic attention during the past few years, serious interest in these catalysts originated with efforts to develop catalytic systems displaying the high activity, convenient work-up, easy separability and recovery, lowtoxicity ${ }^{16}$.

Metal nanoparticles exhibit unique properties on optical, electronic and chemical behavior which is quite different from bulk metal materials due to quantum size effect, surface effect and others effects ${ }^{17-19}$. Transition metal nanoparticles as good catalysts for organic synthesis have attracted much attention over the past decade ${ }^{20-23}$. But the liquid suspensions of metal nanoparticles in catalysis will bring some problems such as in recycle and the separation of the catalyst from reaction system. Thus, some work focused on immobilizing metal nanoparticles on suitable support materials. Actually, many immobilization methods and polymeric support materials used to catalyze the Suzuki-Miyaura reaction have been reported in literature ${ }^{24-27}$. All these catalysts show good catalytic activity for the Suzuki-Miyaura reaction, but the preparations of the catalyst supports involve many steps. Poly(vinyl chloride) (PVC) modified by functional group can be prepared via displacement reaction directly without chloromethylation and makes its inexpensive and practical support for heterogeneous catalyst. To development of simple and reliable protocols for the immobilization of catalytically active palladium nanoparticles on functionalized PVC, herein, we report the synthesis and characterization of one kind of poly(vinyl chloride)-pyrudinium resin supported nanopalladium catalyst and the application of it in Suzuki-Miyaura reaction of aryl halides with arylboronic acids that can afford excellent yield in the air.

\section{Experimental}

Melting points were measured by X6 micromelting point apparatus and uncorrected. Infrared spectra were recorded using $\mathrm{KBr}$ pellet on a Nicolet 2700 spectrometer. ${ }^{1} \mathrm{H}$ NMR spectra were recorded on a Bruker AVANCE 300 instrument at $300 \mathrm{MHz}$ in DMSO- $\mathrm{d}_{6}$ using TMS as the internal standard. The elemental analyses were performed on a Perkin Elmer EA2400II elemental analyzer. The contents of elemental palladium in the polymeric catalyst were determined by Perkin Elmer Optima 2000DV inductive coupled plasma (ICP) spectroscopy. Scanning electron microscopy (SEM) was performed with Philips XL 30ESEM instrument. Transmission electron microscopy (TEM) was performed with a Philips Tecnai instrument operating at $40-100 \mathrm{kV}$. All chemicals used were of commercial grade without further purification.

\section{General procedure for the synthesis $P V C-P y-P d^{0}$ catalyst}

To a $250 \mathrm{~mL}$ three-necked flask was added pyridine $(30.0 \mathrm{~mL}, 0.375 \mathrm{~mol})$, sodium hydroxide $(24.0 \mathrm{~g}, 0.6 \mathrm{~mol})$ and water $(45 \mathrm{~mL})$. To the solution poly(vinyl chloride) $(15.0 \mathrm{~g})$ was added and the reaction mixture and stirred below $60{ }^{\circ} \mathrm{C}$ for $3 \mathrm{~h}$, then stirred at $95-100{ }^{\circ} \mathrm{C}$ for another $16 \mathrm{~h}$. After cooling to the room temperature, the mixture was poured into $500 \mathrm{~mL}$ water, filtered and washed with water $(3 \times 20 \mathrm{~mL})$ and $95 \%$ ethanol $(3 \times 20 \mathrm{~mL})$. The as-prepared resin was then treated with $\mathrm{PdCl}_{2}(2.0 \mathrm{~g}, 9.4 \mathrm{mmol})$ in $95 \%$ ethanol $(100.0 \mathrm{~mL})$ for $48 \mathrm{~h}$ yielding the elemental analysis. Metal content of PVC-Py-Pd ${ }^{0}$ was found to be $0.22 \mathrm{mmol} / \mathrm{g}$ by ICP. 


\section{General procedure for the PVC-Py-Pd catalyzed Suzuki-Mayaura cross-coupling reaction}

The PVC-Py-Pd ${ }^{0}$ catalyst ( $3.6 \mathrm{~mol} \% \mathrm{Pd}$ ), phenylboronic acid (150 mg, $1.2 \mathrm{mmol}$ ), $\mathrm{K}_{2} \mathrm{CO}_{3}$ (280 mg, $2.0 \mathrm{mmol})$ and aryl halides $(1.0 \mathrm{mmol})$ were added to a $25.0 \mathrm{~mL}$ reaction flask containing $95 \%$ ethanol $(10.0 \mathrm{~mL})$. The mixture was heated to $78{ }^{\circ} \mathrm{C}$ and stirred for the specific time indicated in Table 2 . The progress of the reaction was monitored by TLC. After the completion of the reaction, the catalyst was filtered off and washed with $95 \%$ ethanol for several times by suction. The filtrate was poured into $50.0 \mathrm{~mL}$ distilled water and the solid materials were filtered and treated with $95 \%$ ethanol. The products were further purified with recrystallisation. All of the products are known and the data are found to be identical with those that reported in literature elsewhere.

\section{Results and Discussion}

\section{Preparation and characterization of $P V C-P y$ and $P V C-P y-P d^{0}$}

Since 'naked' nanoparticles are kinetically unstable in solution, all preparation methods must use stabilizing agents, which adsorb at the particle surface. There are three types of nanoparticles stabilization: electrostatic stabilization (anions and cations associate with the NPs), steric stabilization, (aggregation is prevented through the adsorption of large molecules) and electrosteric stabilization (combining both steric and electrostatic effects) ${ }^{28}$. To obtain the stable nanopalladium immobilized on the surface of polymer via electrosteric stabilization effects, we design a new polymer-supported pyridinium cation resin and use it as both steric and electrosteric stabilizing agents. The palladium nanocluster stabilized model was illustrated in Figure 1.

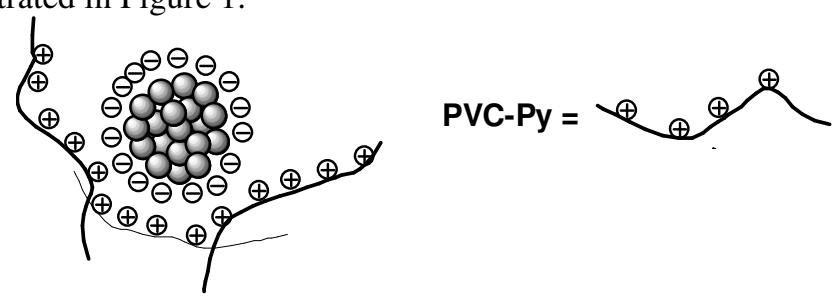

Figure 1. Schematic model illustrating the palladium nanocluster immobilized on the surface of the ionic polymer

The preparation of the PVC-Py involved the addition of an excess of pyridine to commercial available PVC resin in water at $80{ }^{\circ} \mathrm{C}$ for the specific time to afford the corresponding functionalized resin. The catalyst $\mathrm{PVC}-\mathrm{Py}-\mathrm{Pd}^{0}$ is directly prepared by simple in situ reduction of ethanolic solution of palladium chloride in the presence of PVC-Py support (Scheme 1).

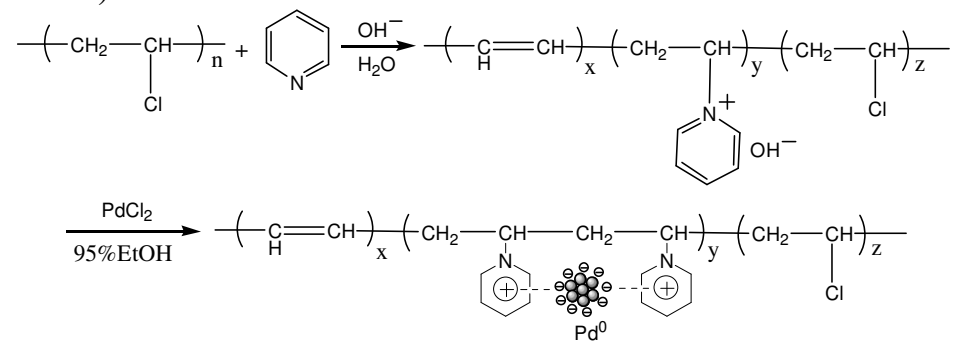

Scheme 1. Preparation of PVC-Py-Pd ${ }^{0}$ catalyst 
The IR spectrum of the PVC-Py showed the characteristic absorption of double bond $(\mathrm{C}=\mathrm{C}$ and $\mathrm{C}=\mathrm{N})$ group at $1640 \mathrm{~cm}^{-1}$. The nitrogen content was found to be $5.06 \mathrm{mmol} / \mathrm{g}$. Metal content in PVC-Py-Pd ${ }^{0}$ catalyst was found to be $0.22 \mathrm{mmol} / \mathrm{g}$ by ICP. The morphology of PVC-Py-Pd ${ }^{0}$ as well as the polymer support PVC-Py, was studied using transmission electron microscopy (TEM). TEM images showed the presence of palladium nanoparticles of $\leq 40 \mathrm{~nm}$ size with the distribution on the surface of polymer matrix (Figure 2).

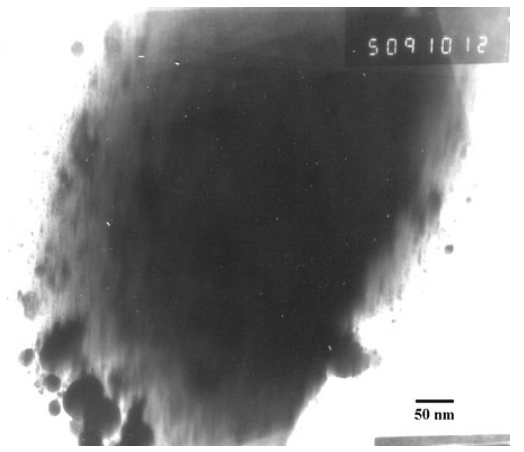

Figure 2. TEM image of fresh prepared PVC-Py-Pd ${ }^{0}$

Thermal stability of the PVC-Py-Pd ${ }^{0}$ has great effect on its catalytic activity and recyclability because Suzuki-Miyaura reaction is usually carried out under heat conditions. Figure 3 shows the TG curves of PVC-Py-Pd ${ }^{0}$ respectively at atmospheric conditions. TG analysis shows that $\mathrm{PVC}-\mathrm{Py}-\mathrm{Pd}^{0}$ are stable up to $174.25^{\circ} \mathrm{C}$ respectively.

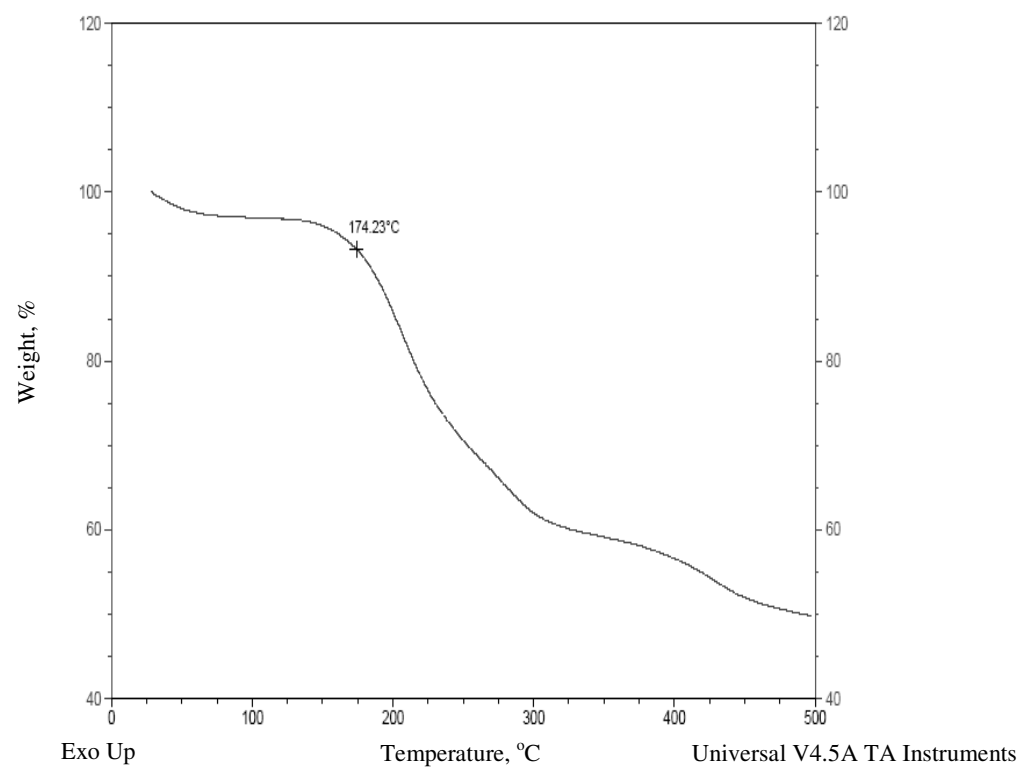

Figure 3. TG curve of PVC-Py-Pd ${ }^{0}$.

\section{Effect of the base on the catalytic performance}

In order to explore the PVC-Py-Pd ${ }^{0}$ nanoparticles catalyst for the Suzuki-Miyaura coupling reaction, the coupling of $p$-nitrobromobenzene and penylboronic acid was chosen as the model reaction to study the effect of different base. As shown in Table 1, the rate of reaction 
and the activity of the catalyst were significantly influenced by the base used. $\mathrm{NaHCO}_{3}$, $\mathrm{NaOH}, \mathrm{K}_{2} \mathrm{CO}_{3}$ and $\mathrm{Na}_{3} \mathrm{PO}_{4} \cdot 12 \mathrm{H}_{2} \mathrm{O}$ were found to be effective in the reaction, $\mathrm{Na}_{2} \mathrm{CO}_{3}, \mathrm{CaO}$ and $\mathrm{Cs}_{2} \mathrm{CO}_{3}$ led to moderate yields of product, while $\mathrm{KOH}$ resulted in a lower yield. Among the bases screened, $\mathrm{K}_{2} \mathrm{CO}_{3}$ was so chosen for the base in the Suzuki-Miyaura reaction with yield up to $99 \%$ and reaction time is less than $1 \mathrm{~h}$.

Table 1. Effect of base on the PVC-Py- $\mathrm{Pd}^{0}$ catalyzed Suzuki-Miyaura cross-coupling reaction of $p$-nitrobromobenzene with penylboronic acid

\begin{tabular}{cccc}
\hline Entry & Base & Reaction time, $\mathrm{h}$ & Yields, $\%^{\mathrm{a}}$ \\
\hline 1 & $\mathrm{Na}_{2} \mathrm{CO}_{3}$ & 7 & 89.5 \\
2 & $\mathrm{NaHCO}_{3}$ & 14.5 & 94.5 \\
3 & $\mathrm{KOH}$ & 1.2 & 78 \\
4 & $\mathrm{CaO}$ & 12 & 83.5 \\
5 & $\mathrm{NaOH}$ & 9.5 & 92.5 \\
6 & $\mathrm{~K}_{2} \mathrm{CO}_{3}$ & 1 & 99 \\
7 & $\mathrm{Na}_{3} \mathrm{PO}_{4} \cdot 12 \mathrm{H}_{2} \mathrm{O}$ & 6 & 92 \\
8 & $\mathrm{Cs}_{2} \mathrm{CO}_{3}$ & 12 & 89 \\
\hline
\end{tabular}

Isolated yield was based on p-nitrobromobenzen

\section{Effect of the amount of the catalyst on the Suzuki-Miyaura reaction}

It is a key issue to note that the amount of palladium catalyst plays an important role in the product yields. The Suzuki-Miyaura reaction of $p$-nitrobromobenzene and penylboronic acid was studied with the amount of catalyst ranging from 0.8 to $5.0 \%$ (Table 2).

Table 2. Effect of the ammount of catalyst on the catalytic performance

\begin{tabular}{cccc}
\hline Entry & Amount of catalyst, mol\% Pd & Reaction time, $\mathrm{h}$ & ${\text { Yields, }{ }^{\mathrm{b}}}^{\mathrm{b}}$ \\
\hline 1 & 0.8 & 1 & 91.5 \\
2 & 2.0 & 1 & 93.3 \\
3 & 3.6 & 1 & 96.0 \\
4 & 5.0 & 1 & 95.4 \\
\hline
\end{tabular}

\section{Isolated yield was based on p-nitrobromobenzene}

It was found that the arylation could be carried out efficiently even with low amount of the catalyst $(0.8 \mathrm{~mol} \% \mathrm{Pd})$ at $78{ }^{\circ} \mathrm{C}$, the yield of the product was $91.5 \%$. Increasing the amount of palladium catalyst gave higher yield until the amount of the catalyst increases to $3.6 \mathrm{~mol} \%$. The yield slightly decreases with the increasing of the amount of palladium catalyst to $5.0 \mathrm{~mol} \%$.

Suzuki-Miyaura reaction of aryl halides with arylboronic acid catalyzed by $P V C-P y-P d^{0}$

On the basis of the optimized reaction conditions, the coupling reactions between a variety of aryl halides and arylboronic acids were carried out to explore the general effectiveness of the PVC-Py-Pd ${ }^{0}$ nanoparticles catalyst (Scheme 2).

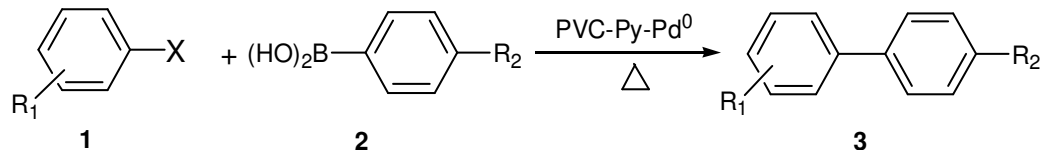

Scheme 2. Suzuki-Miyaura coupling reaction catalyzed by PVC-Py-Pd ${ }^{0}$

The results were listed in Table 3. 
Table 3. PVC-Py- $\mathrm{Pd}^{0}$ catalyzed Suzuki-Mayaura cross-coupling reaction of different aryl halides and aryboronic acids

\begin{tabular}{|c|c|c|c|c|c|}
\hline Entry & $\operatorname{ArX}(1)$ & Arylboronic acid (2) & Products (3) & Time, h & Yields, $\%^{\mathrm{b}}$ \\
\hline 1 & 《 & $\|-\mathrm{B}(\mathrm{OH})_{2}$ & & 1 & 68 \\
\hline 2 & 世 & $\mathrm{H}_{3} \mathrm{CO}-\left\langle-\mathrm{B}(\mathrm{OH})_{2}\right.$ & & 1 & 97 \\
\hline 3 & & $\mathrm{Cl} \longrightarrow \mathrm{B}(\mathrm{OH})_{2}$ & & 1 & 90 \\
\hline 4 & & $3(\mathrm{OH})_{2}$ & & 3 & 66 \\
\hline 5 & $\mathrm{Br}$ & $\mathrm{H}_{3} \mathrm{CO}-\llbracket-\mathrm{B}(\mathrm{OH})_{2}$ & $\mathrm{H}_{3}$ & 1 & 91 \\
\hline 6 & & $\mathrm{Cl}-\mathrm{B}(\mathrm{OH})_{2}$ & & 3.5 & 86 \\
\hline 7 & & $(\mathrm{OH})_{2}$ & & 48 & trace \\
\hline 8 & & 1) $-\mathrm{B}(\mathrm{OH})_{2}$ & $\mathrm{H}_{3} \mathrm{C}$ & 48 & trace \\
\hline 9 & & $\mathrm{Cl}-\left(-\mathrm{B}(\mathrm{OH})_{2}\right.$ & & 48 & trace \\
\hline 10 & $\mathrm{H}_{3} \mathrm{CC}$ & $\mathrm{B}(\mathrm{OH})_{2}$ & $\mathrm{H}_{3} \mathrm{CC}$ & 1 & 92 \\
\hline 11 & $\mathrm{H}_{3} \mathrm{CC}$ & $\mathrm{H}_{3} \mathrm{CO}-\mathrm{B}(\mathrm{OH})_{2}$ & $\mathrm{H}_{3} \mathrm{CO}-0 \mathrm{OCH}_{3}$ & 1 & 95 \\
\hline 12 & $\mathrm{H}_{3} \mathrm{CC}$ & $\mathrm{Cl}-\mathrm{B}(\mathrm{OH})_{2}$ & $\mathrm{H}_{3} \mathrm{CO}\langle-\|-\mathrm{Cl}$ & 1 & 93 \\
\hline 13 & $\mathrm{H}_{3} \mathrm{CO}$ & \#- $\mathrm{B}(\mathrm{OH})_{2}$ & $\mathrm{H}_{3} \mathrm{C}$ & 1 & 90 \\
\hline 14 & $\mathrm{H}_{3} \mathrm{CO}$ & $\mathrm{H}_{3} \mathrm{CO}-\llbracket-\mathrm{B}(\mathrm{OH})_{2}$ & $\mathrm{OCH}_{3}$ & 1 & 87 \\
\hline 15 & $\mathrm{H}_{3} \mathrm{CC}$ & $-\mathrm{B}(\mathrm{OH})_{2}$ & 1) $-\mathrm{Cl}$ & 1 & 90 \\
\hline 16 & $\mathrm{H}_{3} \mathrm{C}$ & $(\mathrm{OH})_{2}$ & & 1 & 83 \\
\hline 17 & $\mathrm{H}_{3} \mathrm{C}$ & 1) $-\mathrm{B}(\mathrm{OH})_{2}$ & $\mathrm{CH}_{3}$ & 1 & 95 \\
\hline 18 & $\mathrm{H}_{3} \mathrm{C}$ & $-\mathrm{B}(\mathrm{OH})_{2}$ & $\mathrm{Cl}$ & 3.5 & 75 \\
\hline 19 & $\mathrm{H}_{3} \mathrm{C}^{-}$ & $(\mathrm{OH})_{2}$ & & 2 & 62 \\
\hline 20 & $\mathrm{H}_{3} \mathrm{C}-$ & $\mathrm{H}_{3} \mathrm{CO}-\mathrm{B}(\mathrm{OH})_{2}$ & - $-\mathrm{OCH}_{3}$ & 1 & 66 \\
\hline 21 & $\mathrm{H}_{3} \mathrm{C}-$ & 1) $\mathrm{B}(\mathrm{OH})_{2}$ & $-\pi \mathrm{Cl}$ & 9.5 & 54 \\
\hline 22 & $\mathrm{O}_{2} \mathrm{~N}$ & $(\mathrm{OH})_{2}$ & & 1 & 96 \\
\hline 23 & $\mathrm{O}_{2} \mathrm{~N}$ & $\mathrm{H}_{3} \mathrm{CO}--\mathrm{B}(\mathrm{OH})_{2}$ & $\mathrm{O}_{2} \mathrm{~N}-\|-0 \mathrm{OCH}_{3}$ & 0.5 & 95 \\
\hline 24 & $\mathrm{O}_{2} \mathrm{~N}$ & 1) $\mathrm{B}(\mathrm{OH})_{2}$ & 1) $\mathrm{Cl}$ & 1 & 90 \\
\hline 25 & $\mathrm{O}_{2} \mathrm{~N}$ & $-\mathrm{B}(\mathrm{OH})_{2}$ & $-F$ & 1 & 96 \\
\hline 26 & $\mathrm{O}_{2} \mathrm{~N}$ & $-\mathrm{B}(\mathrm{OH})_{2}$ & & 1 & 95 \\
\hline 27 & $\mathrm{O}_{2} \mathrm{~N}-^{-}$ & $\mathrm{B}(\mathrm{OH})_{2}$ & & 1 & 99 \\
\hline 28 & $\mathrm{O}_{2} \mathrm{~N}-$ & $\mathrm{H}_{3} \mathrm{CO}--\mathrm{B}(\mathrm{OH})_{2}$ & $-\mathrm{OCH}_{3}$ & 1 & 96 \\
\hline 29 & $\mathrm{O}_{2} \mathrm{~N}-$ & $\mathrm{Cl} \longrightarrow \mathrm{B}(\mathrm{OH})_{2}$ & 1) $-\mathrm{Cl}$ & 1 & 96 \\
\hline 30 & & $3(\mathrm{OH})_{2}$ & & 3.5 & 96 \\
\hline 31 & & $\mathrm{H}_{3} \mathrm{CO}-\square-\mathrm{B}(\mathrm{OH})_{2}$ & $\mathrm{O}_{2} \mathrm{~N}$ & 1.1 & 94 \\
\hline 32 & $\mathrm{O}_{2} \mathrm{~N}$ & $\mathrm{Cl}-\mathrm{B}(\mathrm{OH})_{2}$ & $\mathrm{O}_{2} \mathrm{~N}$ & 17 & 98 \\
\hline 33 & $\mathrm{H}_{2} \mathrm{~N}-\triangle-\mathrm{I}$ & 《) $\mathrm{B}(\mathrm{OH})_{2}$ & $\mathrm{H}_{2} \wedge$ & 1 & 92 \\
\hline 34 & $\mathrm{H}_{2} \mathrm{~N}-\square-\mathrm{I}$ & $\mathrm{H}_{3} \mathrm{CO}-\mathrm{B}(\mathrm{OH})_{2}$ & $\mathrm{H}_{2} \mathrm{~N}-\|-0 \mathrm{OCH}_{3}$ & 1 & 96 \\
\hline 35 & $\mathrm{H}_{2} \mathrm{~N}-\leadsto-\mathrm{I}$ & $\mathrm{Cl} \rightarrow \mathrm{B}(\mathrm{OH})_{2}$ & $\mathrm{H}_{2} \mathrm{~N}-10-\mathrm{Cl}$ & 12 & 93 \\
\hline
\end{tabular}

Isolated yield was based on the aryl halides 
As illustrated in Table 3, the PVC-Py-Pd ${ }^{0}$ catalyst was applicable to a wide range of aryl iodides and bromides substrates to give the products with good to excellent yields. Under the same condition mentioned above, when aryl bromides were employed, a longer reaction time was required and lower yields were observed than those of aryl iodides. Most importantly, aryl iodides with either eletron-donating or eletron-withdrawing substituents have no obvious effect on the yields.

Reusability of $P V C-P y-P d^{0}$ catalyst

One of the main aims of our study was to investigate the reuse of and recycling the catalyst. Finally, we explored the reusability of the PVC-Py- $\mathrm{Pd}^{0}$ catalyst using the reaction of $p$-nitrobromobenzene with phenylboronic acid for the model reaction. After the first run, the catalyst (3.6 mol\% Pd) was filtered and extensively washed with $\mathrm{EtOH}, \mathrm{Et}_{2} \mathrm{O}$ and dried in vacuo. Then the catalyst was directly reused under the same conditions mentioned above. The results listed in Table 4.

Table 4. Recycling and reuse of PVC-Py-Pd ${ }^{0}$ in Suzuki-Miyaura reaction

\begin{tabular}{ccc}
\hline Entry & Reaction time, $\mathrm{h}$ & ${\text { Yields, }{ }^{\mathrm{a}}}^{\mathrm{a}}$ \\
\hline 1 & 2 & 98.5 \\
2 & 3.5 & 96.0 \\
3 & 4 & 95.0 \\
4 & 4 & 93.5 \\
5 & 4 & 93.5 \\
6 & 4 & 95.0 \\
\hline
\end{tabular}

Isolated yield was based on p-nitrobromobenzene

It can be seen from the results that the catalyst could be reused up to 6 runs while retaining the catalytic activity. Characterization of the reused catalysts by transmission electron microscopy (TEM) showed that the nanopalladium has no apparently deactivation could be correlated to the no agglomeration of size $\leq 40 \mathrm{~nm}$ (Figure 4).

\section{Conclusion}

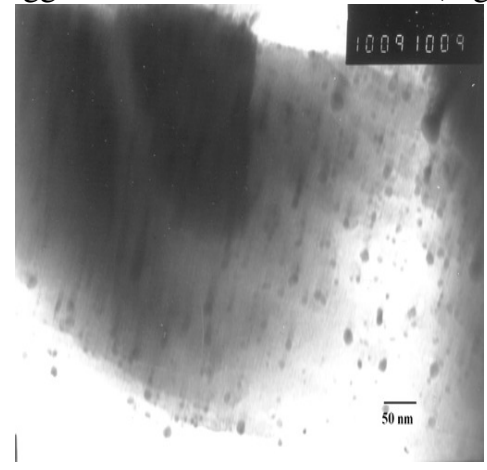

Figure 4. TEM image of PVC-Py-Pd ${ }^{0}$ after reused 6 runs

In conclusion, PVC-Py- $\mathrm{Pd}^{0}$ has been prepared easily by using inexpensive support and exhibit high activity toward the Suzuki-Miyaura reaction of aryl halides with arylphenyl boronic acids in the air. This procedure offers several advantages such as short reaction time, simple experimental and isolated procedure, satisfactory yields of products, as well as excellent catalytic activity and reusability. Further application of the catalyst system to other palladium-catalyzed transformations is on progress. 


\section{Acknowledgment}

This work was financially supported by the National Natural Science Foundation of China (No 21072077) and the Guangdong Natural Science Foundation (No 10151063201000051).

\section{References}

1. Miyaura N and Suzuki A, Chem Rev., 1995, 95, 2457.

2. Stanforth S P, Tetrahedron, 1998, 54(3-4), 263-303.

3. Suzuki A, J Organomet Chem., 1999, 576, 147-168.

4. Bedford R B, Chem Commun., 2003, 1787-1796.

5. Nájera C, Gil-Moltó J, Karlström S and Falvello L R, Org Lett., 2003, 5, 1451-1454.

6. Szmant H H, Organic Building Blocks of the Chemical Industry, Wiley, New York, 1989, 512-518.

7. Nicolaou K C, Li H, Boddy C N C, Ramanjulu J M, Yue T Y, Natarajan S, Chu X J, Brase S and Rubsam F, Chem Eur J., 1999, 5, 2584-2601.

8. Nicolaou K C, Koumbis A E, Takayanagi M, Natarajan S, Jain N F, Bando T, Li H and Hughes R, Chem Eur J., 1999, 5, 2622-2647.

9. Kamikawa K, Watanabe T, Daimon A and Uemura M, Tetrahedron, 2000, 56, 2325-2337.

10. Diederich F and Stang P J, Eds., Metal-Catalyzed Cross-Coupling Reactions, WileyVCH, Weinheim, 1998.

11. De Meijere A and Diederich F, Eds., Metal-Catalyzed Cross-Coupling Reactions; Wiley-VCH, Weinheim, 2004.

12. Collman J P, Hegedus L S, Norton J R and Finke R G, Principles and Applications of Organotransition Metal Chemistry; University Science Books, Mill Valley, CA, 1987.

13. de Miguel Y R, J Chem Soc Perkin Trans 1, 2000, 4213-4221.

14. Shuttleworth S J, Allin S M, Wilson R D and Nasturica D, Synthesis, 2000, 1035.

15. Loch J A and Crabtree R H, Pure Appl Chem., 2001, 73, 119-128.

16. Beletskaya I P and Cheprakov A V, Chem Rev., 2000, 100, 3009.

17. Schmid G, Bäumle M, Geerkens M, Heim I, Osemann C and Sawitowski T, Chem Soc Rev., 1999, 28, 179.

18. Rao C N R and Cheetham A K, J Mater Chem., 2001, 11, 2887-2894.

19. Daniel M-C and Astruc D, Chem Rev., 2004, 104, 293-346.

20. Schulz J, Roucoux A and Patin H, Chem Rev., 2002, 102, 3757.

21. Astruc D, Lu F and Aranzaes J R, Angew Chem Int Ed., 2005, 44, 7852-7872.

22. Raimondi F, Scherer GG, Kötz R and Wokaun A, Angew Chem Int Ed., 2005, 44, 2190-2209.

23. Moreno-Manas M and Pleixats R, Acc Chem Res., 2003, 36, 638.

24. Phan N T S, Van Der Sluys M and Jones C W, Adv Synth Catal., 2006, 348, 609-679.

25. Alonso F, Beletskaya I P and Yus M, Tetrahedron, 2008, 64, 3047-3101.

26. Al-Hashimi M, Sullivan A C and Wilson J R H, J Mol Catal A: Chem., 2007, 273(1-2), 298-302;

27. Song D and Yi W B, J Mol Catal A: Chem., 2008, 280, 20.

28. Pachón L D and Rothenberg G, Appl Organomet Chem., 2008, 22, 288-299. 


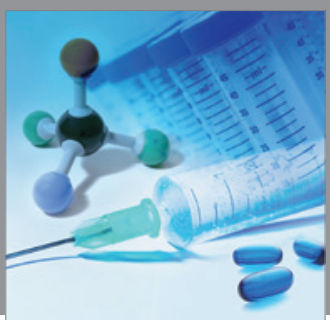

International Journal of

Medicinal Chemistry

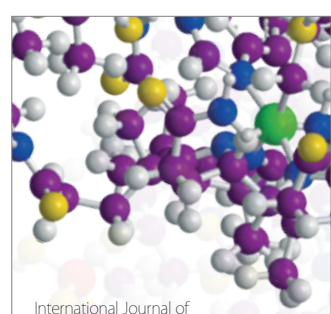

Carbohydrate Chemistry

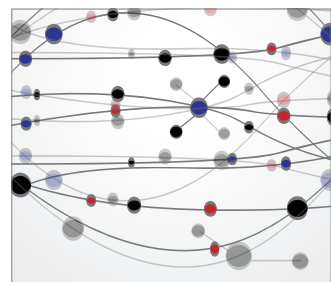

The Scientific World Journal
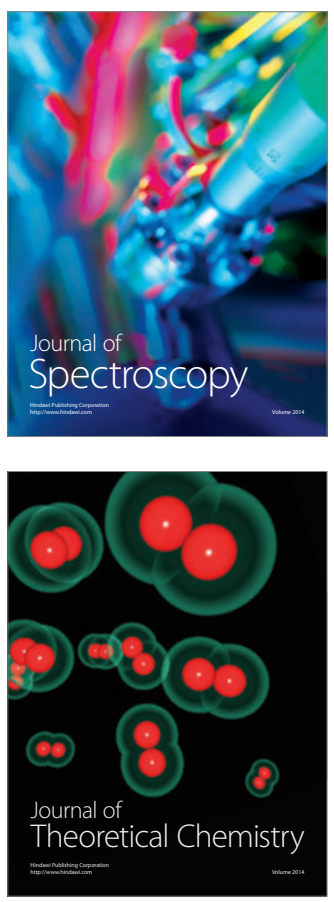
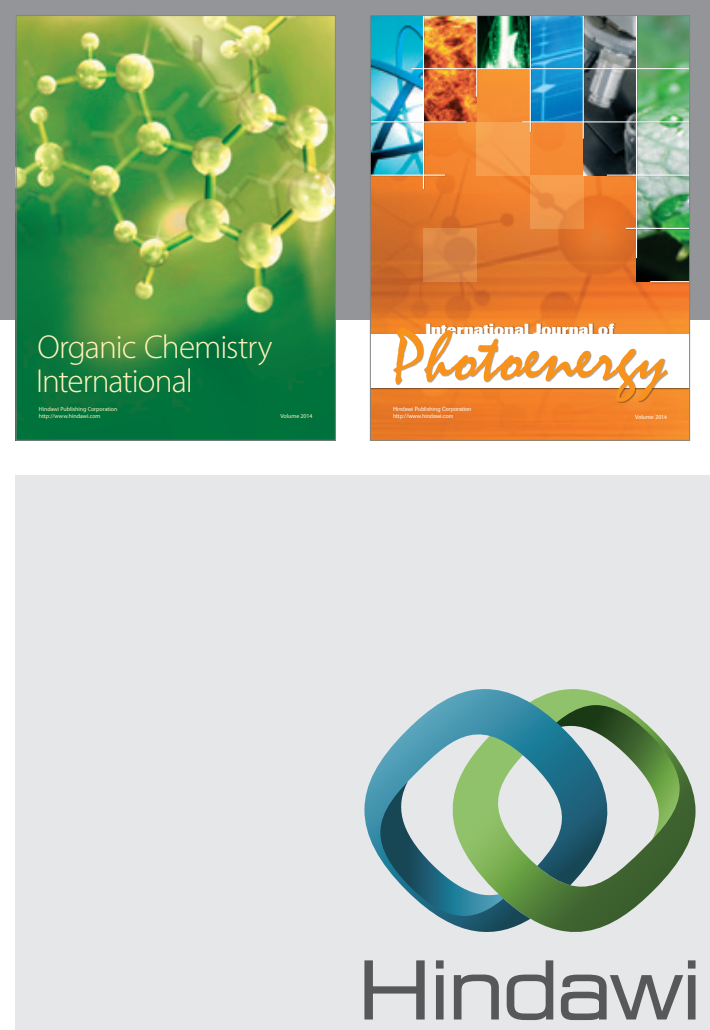

Submit your manuscripts at

http://www.hindawi.com
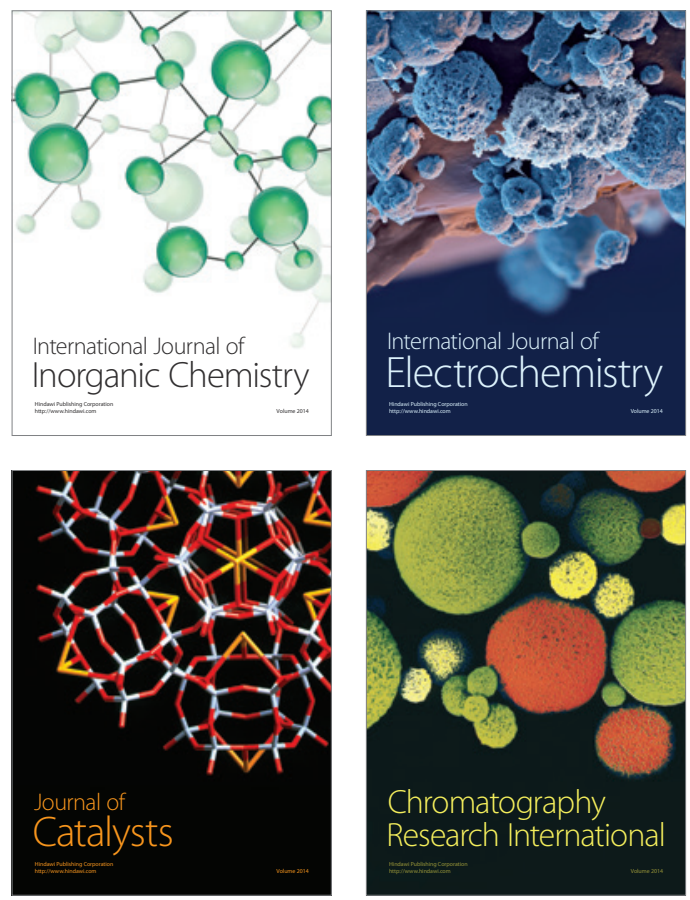
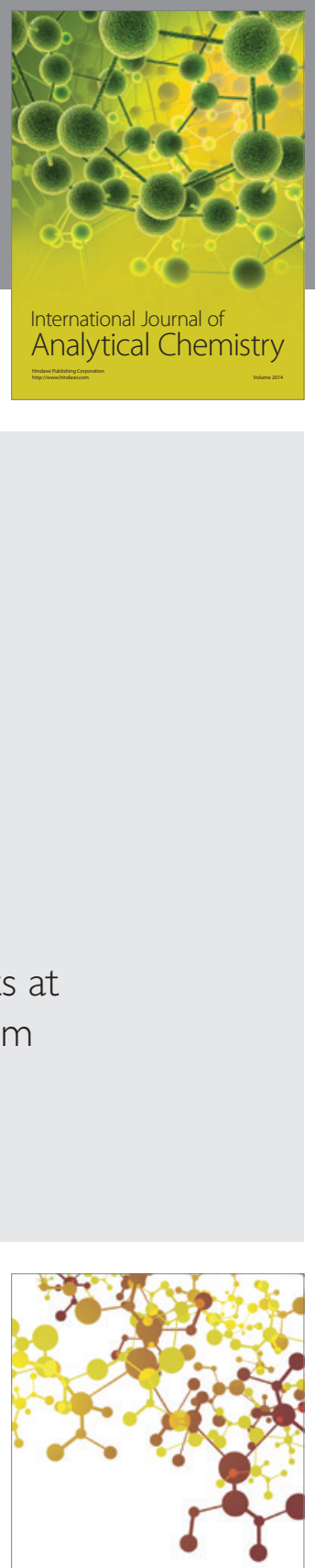

Journal of

Applied Chemistry
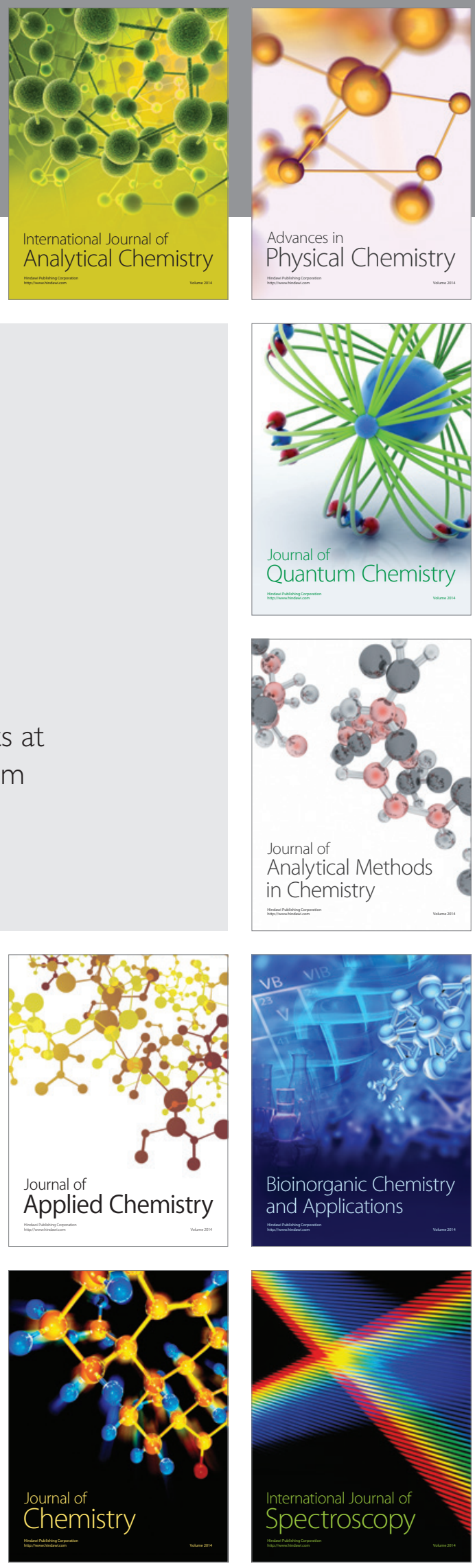